\title{
SHIFTING THE RESPONSIBILITY
}

The BDJ Upfront section includes editorials, letters, news, book reviews and interviews. Please direct your correspondence to the News Editor, Kate Quinlan at the BDJ, The Macmillan Building, 4 Crinan Street, London, N1 9XW or by email to BDJNews@nature.com

Press releases or articles may be edited, and should include a colour photograph if possible.

\author{
Stephen Hancocks OBE \\ Editor-in-Chief
}

$\mathrm{T}$ here is a happy cynicism which runs along the lines of expressing the thought that dentistry would be so very much more enjoyable if it wasn't for the patients. We do not mean it of course and it is not a sentiment exclusive to dental care; many professions and occupations in which there is an element of dealing with the public harbour similar whims which reflect the difficulties inherent in managing the vagaries of human personalities, moods and idiosyncrasies.

The other real truths are that patients need us and we need patients. Our care for them is central to all that we do and is often given as a primary reason for entering dentistry as a career; to help people. As well as the personal, face-to-face or hands-in-mouth care that we provide there is also a wider variety in which we variously participate on a societal level. Recently we have seen two very laudable initiatives by the British Periodontal Society (BPS) and the British Orthodontic Society (BOS) which are aimed specifically at the public, at patients or potential patients and which are funded wholly or partly by those organisations for the greater good.

The BPS have launched a campaign about periodontal disease entitled howsyoursmile? Complete with website (www. bsperio.org.uk/howsyoursmile), the awareness programme includes videos, templates to enable amusing 'selfies', a quiz and various educational elements. Initiated in conjunction with the European Gum Health Awareness Day in May 2016, the work also builds on previous innovations such as the video

\section{'Surely it is \\ the respon-} sibility of

the pro-

fession

to estab-

lish the

evidence

behind such

claims...'

r

such as lingual appliances and shorter treatment periods. The advice, as with the periodontal campaign, includes a video, and has a downloadable PDF with a section on "what questions should I ask my orthodontist or dentist?' The list is comprehensive: How long will the treatment take? Will the end result be stable? Will I have to wear retainers? What are the risks of treatment? How much will the treatment cost in total? Does this include any breakages and retainers? Will I be treated by an orthodontist/dentist or an orthodontic therapist?

Additionally, and quite exhaustively, in the section 'What should I expect from my orthodontist or dentist?' the patient is also advised that; 'a diligent orthodontist or dentist will always: ask you about your concerns, outline all the different treatment options and their risks and benefits, explain about the different types of braces, explain about retainers at the start of treatment, and the possible need for lifelong wear if the teeth are to stay in their new place, explain how likely the teeth are to stay in their new position at the end of treatment tell you how much orthodontic training they have had.
These are elements of the BOS initiative which slightly trouble me. It is not a criticism of the Society, its motives or indeed its execution of the scheme. Rather it is a concern that in advising the patient to ask these questions of a practitioner prior to the possible commencement of treatment we are in danger not only of shifting the responsibility but that we are in effect asking them to clarify what we as a profession should already have sorted out. Bluntly, this includes the ability of a dentist to successfully undertake a proposed course of treatment and provide the information on which a patient can make an informed decision and give meaningful consent.

This does not represent the whole responsibility but it does imply that the onus is on the user to sort out the truth of among other things the advertised claims from manufacturers and distributors of the treatment systems. Surely it is the responsibility of the profession to establish the evidence behind such claims, the robustness of the systems themselves and the competency required to bring them to a satisfactory conclusion for patients, and thus the parameters within which such treatment should be offered?

Checks and balances are in place, complaints systems, the GDC, the law and so forth, but these are measures too far along the spectrum upon which a caring profession should seek to fall back. Reaching out to the public is very good and both societies should be congratulated. However, the situation should give us all pause for thought. Undeniably dentistry would be very much more enjoyable if it weren't for the need to organise it but the truth is that we cannot shift that responsibility without serious repercussions.

DOI: $10.1038 /$ sj.bdj.2016.389 